\title{
PRESTAÇÃO DE SERVIÇOS À ADMINISTRAÇÃO PÚBLICA APÓS O FIM DO PRAZO CONTRATUAL
}

\begin{abstract}
Alexandre Santos de ARagão*
I - Introdução. II - A natureza jurídica dos serviços prestados e a obrigação da Administração Pública em ressarci-los. III - $O$ Quantum do ressarcimento. IV - O pagamento deverá ser feito mediante termo de ajuste de contas. V-Imprescindibilidade da apuração de eventuais responsabilidades funcionais. VI-Conclusão.
\end{abstract}

\section{I - Introdução}

A situação que será tratada é de grande incidência prática. Ocorre sempre que a Administração Pública não toma as providências necessárias para que, chegando a termo um contrato de prestação de serviços de trato continuado, já exista um novo contrato assinado, evitando-se, assim, solução de continuidade na prestação dos serviços.

Muitas vezes, seja por negligência ou lentidão da própria Administração, seja por fatos alheios à sua esfera (v.g., liminar suspensiva do curso de licitação), encerra-se o contrato em vigor, sem que a licitação, os procedimentos prévios à contratação direta (art. 26, Parágrafo Único, Lei 8.666/93), ou mesmo a formalização da prorrogação do prazo contratual (art. 57, II, Lei 8.666/93) tenham sido concluídos. Nestes casos, freqüentemente, a Administração Pública permite, ou mesmo solicita, que a empresa cujo contrato extinguiu-se continue prestando-os.

É sobre a natureza jurídica e o quantum do ressarcimento de serviços prestados sem a devida cobertura contratual que se deitará o foco do presente estudo. 
II - A natureza jurídica dos serviços prestados e a obrigação da Administração Pública em ressarci-los

Extintos contratos administrativos, sem que a contratada deixe de continuar prestando os serviços originariamente contratados, é óbvio que o faz com o assentimento, tácito que seja, não formalizado, da Administração Pública.

Constata-se, então, que, apenas impropriamente, poder-se-ia dizer que os serviços foram prestados "sem cobertura contratual", sendo mais apropriado referir-se a serviços prestados "sem cobertura contratual válida".

Se há consentimento, há contrato, que, entretanto, será nulo, seja por vício de forma (contrato oral ou tácito), seja pela não precedência de licitação ou dos procedimentos estabelecidos para as hipóteses de contratação direta ou prorrogação do contrato.

Ressalte-se que a caracterização do contrato como nulo ou inexistente não tem qualquer relevância na seara do Direito Administrativo, já que, "em razão da formalidade obrigatória e da presunção de legalidade, $o$ ato inexistente se assimila ao ato inválido." Mesmo no Direito Privado, a distinção não alteraria os efeitos do enriquecimento sem causa, a serem adiante analisados.

Pois bem: diante de um contrato nulo, o art. 59, Parágrafo Único da Lei 8.666/93, contemplando, no âmbito dos contratos administrativos, o princípio da vedação do enriquecimento sem causa, dispôs que "a nulidade não exonera a Administração do dever de indenizar o contratado pelo que este houver executado até a data em que ela for declarada, e por outros prejuízos regularmente comprovados, contanto que não lhe seja imputável, promovendo-se a responsabilidade de quem lhe deu causa".

Com efeito, já pelos princípios da Teoria Geral do Direito, aplicáveis a todos os seus ramos, não se permitiria ao Estado enriquecer-se à custa de serviços prestados sem nenhuma contrapartida.

A respeito, ULPIANO já dizia: "in quid quod factus sit locupletior, aequissimum erit in dari in repe titionem; nec enim debet ex alieno damno esse locuples".

Esse princípio universal de direito, que nos legou o direito romano, "deve ser admitido de maneira geral, como sanção da regra de eqüidade de que não é permitido a ninguém enriquecer injustamente à custa de outrem: jure naturae aequum est, neminem cum alterius detrimento et injuria locupletatiorem fieri". ${ }^{2}$

No âmbito do Direito Administrativo, e especialmente quanto aos serviços prestados em virtude de contratos administrativos nulos ou inexistentes, a doutrina é uníssona na aplicação do aludido princípio geral de direito:

"Mas mesmo no caso de contrato nulo, pode tornar-se devido o pagamento dos trabalhos realizados ou dos fornecimentos feitos à Administração, uma vez que tal pagamento não se funda em obrigação contratual, e sim no dever moral de indenizar

1 Diogo de Figueiredo Moreira Neto, in "Curso de Direito Administrativo", Editora Forense, $9^{2}$ edição, pág. 155 .

2 J. M. CARVALHO SANTOS, in "Código Civil Brasileiro Interpretado", Vol. XII, Livraria Freitas Bastos, $7^{\text {a }}$ edição, pág. 383. 
toda a obra, serviço ou material recebido e auferido pelo Poder Público, ainda que sem contrato ou com contrato nulo, porque o Estado não pode tirar proveito da atividade do particular sem a correspondente indenização." 3

"A responsabilidade não é contratual, mas sim extracontratual, eis que conseqüente à anulação do ato, portanto, decorre de fato administrativo." 4

Vê-se, portanto, que a Administração Pública deve ressarcir os serviços prestados após o termo do prazo contratual, não sendo esta obrigação, todavia, de caráter contratual, mas, sim, extracontratual, proveniente da vedação do enriquecimento sem causa, distinção que, adianta-se, será de grande importância para a definição do quantum a ser ressarcido (cf. próximo item).

Oportuno lembrar que sequer seria cogitável a celebração de um novo contrato com efeitos pretéritos para legitimar a prestação de serviços já consumada, uma vez que dos próprios sistemas orçamentários e de realização de despesas da Lei $\mathrm{n}^{\mathrm{O}}$ 8.666/93 e da Lei $n^{0} 4.320 / 64$ extrai-se a vedação à atribuição de efeitos pretéritos aos contratos administrativos.

Se antes do advento da Lei 8.666/93, esta já era a única orientação possível, $a$ fortiori agora, face aos eloqüentes vetos presidenciais apostos aos $\$ \S 2^{\circ}$ e $3^{\circ}$ do art. 61 do respectivo projeto de lei, que admitiam, em casos excepcionalíssimos, contratos administrativos com efeitos retroativos.

\section{III - $O$ Quantum do ressarcimento}

Fixada a obrigação do Estado em ressarcir o prestador de serviços, cabe delimitá-la quantitativamente, definindo quais elementos indenizatórios deve contemplar.

Destaca-se, que este ponto pouco ou quase nada tem sido abordado pela doutrina e jurisprudência, administrativa ou judicial, sendo a praxe administrativa no sentido de ressarcir o particular sem maiores questionamentos, com o pagamento dos preços ajustados no contrato já extinto.

Entendemos, no entanto, que a Administração Pública deve ao prestador de serviços apenas os danos emergentes, ou seja, o preço de custo, com os acréscimos legais, excluídos eventuais lucros cessantes, lucros estes que auferiria em situação de normalidade jurídica, isto é, se a obrigação da Administração Pública em efetuar o pagamento adviesse de contrato, não do enriquecimento sem causa (cf. item II supra).

As condições necessárias à verificação do enriquecimento sem causa são: o enriquecimento de alguém, o empobrecimento de outrem e a ausência de justa causa para ambos. No caso do enriquecimento ser superior ao empobrecimento, o ressar-

3 HELY LOPES MEIRELLES, in "Licitação e Contrato Administrativo", Ed. RT, 10ª ed., pág. 232

- os grifos são do próprio autor.

4 LÚCIA VALLE FIGUEIREDO, in "Curso de Direito Administrativo", ed. Malheiros, 1994, pág. 336

- os grifos são da autora. 
cimento se conterá nos limites deste, ou seja. do prejuízo efetivamente havido, não alcançando a integralidade do valor do enriquecimento da parte que se locupletou. Vê-se, portanto, que o que é ilícito não é se enriquecer sem justa causa, mas, sim, enriquecer-se sem justa causa, à custa do empobrecimento de outrem.

A tese ora defendida já tem sido há tempos reiterada pelos Mestres da Teoria Geral do Direito, como se infere do seguinte excerto do eminente CUNHA GONÇALVES, invocado por J. M. CARVALHO SANTOS:

"... a própria palavra "restituição" mostra que a indenização deve ser limitada aos danos emergentes. Se o proveito de um fôr superior ao prejuízo do outro, não poderá este reclamar a importância total dêsse proveito, porque a diferença não constitui o seu detrimento." 5

É exatamente esta a hipótese ora tratada, em que a Administração Pública tem um locupletamento maior que o empobrecimento do prestador de serviços, deixando de pagar pelos serviços prestados o preço de custo mais o lucro próprio da atividade empresarial, ao passo que o prestador deixou de auferi-los, tendo, porém, como prejuízo, como detrimento, apenas o valor do preço de custo, devendo, por via de consequiência, o ressarcimento, oriundo não de contrato, mas do enriquecimento sem causa, compreender apenas o preço de custo, sem a inclusão de qualquer lucro.

O Direito Positivo, ao tratar das indenizações e seus componentes, corrobora este entendimento. $\mathrm{O}$ art. 1.059 do Código Civil, que trata das obrigações pecuniárias em sub-rogação, isto é, advindas do inadimplemento de obrigações, originariamente de dar, fazer ou não fazer, faz alusão aos lucros cessantes, mas o art. 1.061, do mesmo Código, disciplinador das obrigações $a b$ ovo pecuniárias, como é a da Administração Pública na hipótese ora tratada, dispõe que as perdas e danos consistem apenas no valor originário acrescido dos juros de mora, custas e eventual pena convencional.

O art. 1.061 do Código Civil deixa claro, portanto, que o inadimplemento das obrigações pecuniárias não acarreta lucros cessantes, tendo entendido o Legislador que estes já estariam abrangidos pelos juros de mora.

Explicitamente neste sentido, o inolvidável CLÓVIS BEVILÁQUA:

"Quando o pagamento consiste em dinheiro, a estimação do dano emergente da execução já se acha previamente estabelecida. Não há que fazer a substituição em dinheiro da prestação devida. Falta avaliar os lucros cessantes. $O$ Código os determina pelos juros de mora e pelas custas." 6

Expondo a subsunção das obrigações do enriquecimento sem causa ao art. 1.061, Código Civil, mais uma vez brilhantemente, J.M. CARVALHO SANTOS:

"Cumpre advertir que o dano, exigido para o enriquecimento ilícito, nada tem de comum com o dano exigido nos casos de indenização dos atos ilícitos. Assim, por exemplo, quando se fala em indenização dos danos motivados por dolo ou culpa de alguém, entende-se que o culpado fica responsável pelo ressarcimento dos pre-

5 in ob. e vol. Cits., pág. 389.

6 in "Código Civil dos E.U.B.", Editora Rio Estácio de Sá, ediçāo histórica, Vol. II, Comentários ao art. 1.061 - os grifos são nossos. 
juízos resultantes do ato, abrangendo todas as conseqüências prejudiciais dele resultantes, ainda que não constituam diminuição do patrimônio. Ao invés, quando se fala em obrigação com apoio no enriquecimento ilícito, não pode entrar no conceito do dano outro critério senão o desfalque, ou perda material, bem como o esforço e energia dispendidas...

Como adverte Cunha Gonçalves, e já havíamos explicado ainda há pouco, a própria palavra restituição mostra que a indenização deve ser limitada aos danos emergentes. Se o proveito de um for superior ao prejuizo do outro, não poderá este reclamar a importância total dêsse proveito, porque a diferença não constitui o seu detrimento." 7

A Lei $\mathrm{n}^{2}$ 8.666/93, em seu art. 59, leva à mesma assertiva. A ver: a) ao dizer que o contrato nulo não produz efeitos (caput) e ao determinar que o Estado ressarça os serviços prestados sem cobertura contratual válida (Parágrafo Único), deixa indene de dúvidas a afirmação segundo a qual esta obrigação, originariamente pecuniária, não é de índole contratual (cf. item I supra); b) confirmando a tese, refere-se apenas a "prejuízos", termo equivalente a danos emergentes e excludente dos lucros cessantes (cf, DE PLÁCIDO E SILVA, in "Vocabulário Jurídico", Ed. Forense, $2^{\mathrm{a}}$ edição, Vol. III, pág. 425).

Data venia, contrário ao bom senso, seria o entendimento segundo o qual o ressarcimento por serviços prestados sem a existência de um contrato administrativo válido abrangesse também os lucros cessantes, devendo o Estado pagar o mesmo valor que desembolsara em virtude do anterior cumprimento do contrato, este, sim, válido. Estaríamos, na prática, ao adotar esse entendimento, igualando uma situação jurídica legítima a outra, atentatória dos princípios da Administração Pública, notadamente o da obrigatoriedade de licitação (art. 37, caput e inc. XXI, C.F.).

Com esteio nos fundamentos expostos, assim pronunciou-se O.A. BANDEIRA DE MELO em sede jurisprudencial:

"Não obstante procedentes as objeções do Município, através do procurador da Prefeitura, da nulidade do contrato de valor de $\mathrm{Cr} \$ 100.000,00$ e da irregularidade da suplementação da verba, não pode êle locupletar-se à custa alheia, e lhe cumpre pagar o serviço feito em proveito da Câmara. Mas como é nulo o contrato, só deve pagar o custo dêsse serviço, jamais o lucro que dêle auferiria a emprêsa jornalística na sua prestação. Por isso, embora confirmasse a sentença na sua tese jurídica, a reformaria nos têrmos em que a aplicou. Condenaria o Município de Moji das Cruzes a pagar, tão-somente, a importância correspondente ao custo do serviço prestado, o que se apuraria em execução, acrescido dos juros da mora e custas em proporção." 8

No mesmo sentido, RODRIGUES ALCKMIN:

"Reconhecida a nulidade do contrato, certo é que a quem contratou, irregularmente, com a Administração Pública, não toca o direito de reclamar os esperados lucros, ou cláusula penal, ou perdas e danos pelo inadimplemento, verbas que, somente se válido o contrato, seriam de pretender. Tem o contratante, porém, o

7 in ob. e vol. cits., págs. 385 e 389 - os grifos são nossos.

8 in RDA, 54/119 - os grifos são nossos. 
direito de obter remuneração pelos serviços prestados, para que não haja injusto enriquecimento da Administração." 9

O valor de custo dos serviços deverá ser apurado em liquidação, em quaisquer das espécies admitidas em Processo Civil, notadamente a feita por artigos, a ser levada a cabo pela Administração Pública, a qual poderá, valendo-se, por exemplo, de pareceres técnicos que afiram qual é a margem de lucro normal naquele ramo de atividade, descontar a percentagem respectiva do valor constante do contrato formal e válido anteriormente celebrado.

Em nada alteraria essas conclusões, o fato de o prestador de serviços estar ou não de boa-fé, ou seja, é irrelevante que esteja ciente ou não dos vícios que inquinam o contrato administrativo.

É evidente em casos tais a má-fé do prestador de serviços, que, até em razão do princípio da obrigatoriedade da Lei (art. $3^{\circ}$, Lei de Introdução ao Código Civil), é sabedor da inadmissibilidade dos contratos administrativos verbais ou tácitos e da exigência de prévia licitação ou regular prorrogação do prazo contratual. Não poderá, portanto, o empresário arguir a sua boa-fé e o caráter essencialmente lucrativo de sua atividade. É inadmissível facultar ao particular, ainda que tenha o beneplácito de agentes públicos, a adoção de atitude sabidamente ilegal para que aufira lucro. O caráter inegavelmente lucrativo de sua atividade não pode chegar ao extremo de assegurar-lhe o lucro mesmo que esteja sendo exercida irregularmente. Veja-se a respeito a melhor doutrina e jurisprudência.

"A ausência de forma escrita acarreta a nulidade do contrato, que não produzirá efeito algum (excetuada a hipótese acima referida). A gravidade da consequiência também se destina a reprimir atuações indevidas e ilícitas. $O$ terceiro não poderá argüir boa-fé ou ignorância da regra legal. Se aceder com contratação verbal, arcará com as conseqüências." 10

"Mas se, no campo do Direito Civil, a validade dos contratos não depende de nenhum formalismo, salvo nos casos expressos em lei, já perante o Direito Administrativo tal não ocorre. $O$ formalismo aí é imperativo e inseparável do conteúdo do contrato.

Por isso não é lícito a quem contrata com o Poder Público alegar a ignorância da lei e as formalidades imprescindíveis para o ato de que participa, impondo-se a observância de todas as cautelas." 11

"Aos contratos administrativos alude a Constituição de 1988: no art. 22, XXVII, para submetê-los a normas gerais federais, e no art. 37, XXI, para exigir o prévio processo licitatório, tendo se tornado, assim, um instituto de assento constitucional.

Há, portanto, disciplina adequada do contrato administrativo, que retira sua cogência da própria Lei Maior: são as normas de Direito Administrativo, que é o

9 in RDA, 54/119 - os grifos são nossos.

10 Marçal Justen Filho, in "Comentários à Lei de Licitaçōes", Ed. Aide, 1993, pág. 351 - os grifos são nossos.

11 TJSP, in RDA. 48/267 - os grifos são nossos. 
direito comum do Direito Público, tanto quanto o Direito Civil é o direito comum do Direito Privado, com expressão, hoje, em nível infraconstitucional, no DecretoLei $\mathrm{n}^{\mathrm{9}} 2.300$, de 21 de novembro de 1986.

É necessário bem compreender que essas normas não se dirigem exclusivamente ao administrador público, como, por exemplo, as de Direito Financeiro, que não tocam a substância da obrigação assumida pelo Estado face ao contratante particular. Ao contrário, por serem normas de direito comum, dirigem-se à Administração e ao administrado por igual, de sorte que uma invalidade que nelas tenha fundamento, toca a substância da obrigação assumida pelo Estado. Ambos os contratantes se sujeitam, assim, à disciplina jurídica estabelecida para os contratos administrativos.

Ora, se como preceitua o art. 44, do DL 2.300/86: "Os contratos administrativos de que trata este decreto-lei regulam-se pelas suas cláusulas e pelos preceitos de direito público, aplicando-se-lhes, supletivamente, disposições de direito privado" e, o art. 50, Parágrafo Único: "É nulo e de nenhum efeito o contrato verbal com a Administração, salvo o de pequenas compras e de pronto pagamento", há que se tomar com muita cautela qualquer presunção de boa fé, atribuída ao administrado."12

Uma observação merece ser feita quanto ao momento que deve ser levado em conta pela Administração Pública para o cálculo do preço de custo dos serviços prestados pelo prestador de serviços.

A Administração Pública deverá ressarcir os preços de custo vigentes à época do pagamento, não levando em conta os da época da prestação dos serviços, razão pela qual sequer se há de falar em correção monetária dos valores a serem ressarcidos.

É o que preleciona J.M. CARVALHO SANTOS:

"Para determinar-se o montante dêsse valor, deve-se, em princípio, e salvo disposição legal em contrário, ter em vista não o momento em que a obrigação de restituir teve nascimento, mas àquele da propositura da ação de in rem verso, que, ao invés do que ocorre com a ação negotiorum gestorum contratia, não é, em geral, dada senão até a concorrência do que o patrimônio do devedor se encontra ainda enriquecido nesta última época." 13

O quantum do ressarcimento deverá no entanto, ser acrescido de juros de mora de seis por cento ao ano (ex vi art. $1.061 \mathrm{c} / \mathrm{c} 1.063$, Código Civil), a serem contados do término da prestação dos serviços.

\section{IV - O pagamento deverá ser feito mediante termo de ajuste de contas}

O termo de ajuste de contas, instrumento adequado para a solução extrajudicial de pendências pecuniárias entre a Administração Pública e administrados, é o meio hábil para se efetuar o ressarcimento delimitado no item anterior.

12 Visto dado pelo Procurador do Estado do Rio de Janeiro Diogo de Figueiredo Moreira Neto ao Ofício $\mathrm{n}^{2} 01 / 91-\mathrm{AM}$.

13 in ob. e vol. cits., pág. 389. 
A lavratura do termo de ajuste de contas, em casos como o analisado, é exigência da Lei Federal $n^{9} 4.320 / 64$ (arts. 60 a 64) e, no caso do Estado do Rio de Janeiro, da Lei Fluminense $\mathrm{n}^{\mathrm{0}} 287$ ( arts. 90 a 95). O pagamento da despesa deve ser precedido da sua liquidação, que deve constar de documento escrito (art. 63, § $2^{\underline{Q}}$, I, Lei 4.320/64 e art. $90, \S 2^{2}$, I, Lei Fluminense 287/90) e possuir o respectivo empenho.

O termo de ajuste deverá conter a descrição e atestação minuciosa dos serviços prestados sem cobertura contratual válida e a quitação sem ressalvas a ser dada pelo prestador de serviços.

Lembra-se, outrossim, que, como observa MARCOS JURUENA VILLELA SOUTO, " a legislação do Estado do Rio de Janeiro exige autorização governamental para celebração de tais ajustes." 14 A celebração de tais termos deverá, portanto, seguir as formalidades estabelecidas na legislação específica de cada entidade administrativa.

\section{$\mathrm{V}$ - Imprescindibilidade da apuração de eventuais responsabilidades funcionais}

A celebração de contrato verbal ou tácito, sem prévia licitação, contratação direta ou regular prorrogação do prazo contratual, além de causa da nulidade do contrato, constitui violação dos deveres funcionais daqueles agentes administrativos que, omissiva ou comissivamente, concorreram para a ocorrência da irregularidade. Tais responsabilidades devem ser apuradas em procedimento administrativo disciplinar, instaurado com este objetivo específico, sob pena de responsabilização também dos que se omitirem nesta apuração.

O eventual argumento de falta de verbas não ilide essa responsabilidade, já que, se o orçamento não destinou verbas para a celebração de dado contrato, foi porque o Poder Político teve outra opção financeira, não cabendo ao administrador, revertendo esta decisão política tomada em conjunto pelo Chefe do Poder Executivo e pelo Poder Legislativo, permitir a prestação de serviços sem a legítima cobertura contratual. Se a verba é pouca, não pode o administrador, em uma falsa solução, contratar verbalmente empresa para permanecer prestando serviços à Administração Pública após o término do prazo contratual.

Corroborando este entendimento, a melhor Jurisprudência Administrativa:

"Percebe-se que a determinação expressa da lei é no sentido da formalização do contrato, da necessária cobertura orçamentária e do cumprimento do rito financeiro que conduza à liquidação e pagamento da despesa. Transgredidos esses comandos, devem ser apuradas responsabilidades sob pena de se sacrificar o conteúdo da norma...

Se, no entanto, não for punido o servidor que descumpriu a lei, uma situação que deveria ser excepcionalíssima torna-se rotina, burlando o sistema vigente de controle.

14 Decreto no 3.149/80, art. 48, §2 , apud "Licitaçōes e Contratos Administrativos", Editora Esplanada, 1993, pág. 202. 
Assim, parece-me que qualquer ajuste de contas dessa espécie deverá ser concomitante à apuração da responsabilidade." 15

A emergência, normalmente alegada pelos administradores para justificar estes contratos verbais ou tácitos, como bem notou o ex-Procurador-Chefe junto ao Tribunal de Contas do Município do Rio de Janeiro, FERNANDO ANTONIO CORREA DE ARAÚJO, a respeito de situação análoga, na maioria das vezes não passa de falta de planejamento:

"Na prática, a situação de "emergência" muitas vezes decorre da falta de planejamento administrativo ou de previsão para necessidades perfeitamente previsíveis. Isto tem sido constantemente detectado por nós nestes anos de trato com o assunto." 16

A nosso ver, não é qualquer "emergência" que pode representar escusa para a responsabilização funcional dos agentes que permitem ou mesmo solicitam a prestação irregular de serviços à Administração Pública, mas apenas circunstâncias excepcionais, que constituam verdadeira força maior ou caso fortuito em seus contornos clássicos.

Irretocável, no ponto, as afirmações de AMILCAR MOTTA:

"Penso que, efetivamente, inteira razão assiste ao órgão jurídico consulente.

Tal como ele, entendo que o termo de ajuste de contas não pode ser convertido numa panacéia milagrosa, nem transformado numa sanatória geral dos erros ou das omissões dos agentes do Poder Público, do mesmo modo como o seu emprego não pode ser desvirtuado na prática diuturna da Administração.

Bem ao revés disto, entendo que a sua utilização deve ficar restrita àqueles casos em que, por motivos de força maior, houver se verificado, concretamente, a impossibilidade prática da formalização, do instrumento que for cabível na espécie.

Note-se: não basta a simples conveniência do administrador, nem é suficiente que haja se verificado a mera dificuldade em poder instrumentar adequadamente $o$ negócio jurídico subjacente, nesse ou naquele caso específico. É preciso mais. É preciso que a impossibilidade seja não apenas superveniente, como, também, irresistível quanto aos efeitos e imprevisível quanto às suas causas e origens.

Em suma, faz-se mister que o fato assuma os contornos clássicos da força maior - tal como se acham descritos na literatura juridica especializada - para que a exclusão possa ser então admitida, em razão da sua anormalidade." 17

\section{$\mathrm{V}$ - Conclusão}

Por todo o exposto, concluímos que: ${ }^{18}$

15 in Parecer da Procuradoria Geral do Estado do Rio de Janeiro, Constante do Ofício n 23/90-EV, de lavra do Procurador ENILTON VIEIRA.

16 citado por Jessé Torres Pereira Júnior, in "Comentários à Nova Lei das Licitações Públicas", Ed. Renovar, 1993, pág. 129.

17 in Ofícios n ${ }^{2 s}$ 28/90-AM e 01/91-AM, da Procuradoria Geral do Estado do Rio de Janeiro.

18 A tese ora exposta foi acolhida em sede administrativa, no âmbito da Procuradoria Geral do Estado do Rio de Janeiro, através do Parecer 04/94 - ASA, de lavra do autor, aprovado pelo Procurador-Chefe 
a) a Administração Pública, enriquecida sem causa, deve ressarcir os serviços prestados pelo prestador de serviços sem cobertura contratual válida;

b) o ressarcimento deverá consistir no valor de custo dos serviços, apurado em liquidação a ser procedida pela Administração Pública, acrescido de juros de mora de seis por cento ao ano a contar do fim da prestação dos serviços, excluidos quaisquer lucros que o prestador de serviços auferiria se estivesse em situação regular, não se podendo, portanto, ressarcir pelo pagamento dos valores anteriormente pactuados em contratos válidos, nos quais estavam, naturalmente, embutidos lucros;

c) não é cabível correção monetária em virtude do valor de custo aludido na letra " $b$ " supra já ser o vigente no momento do pagamento a ser efetuado;

d) o pagamento deverá ser instrumentalizado por Termo de Ajuste de Contas;

e) a responsabilidade funcional dos agentes administrativos que, omissiva ou comissivamente, cooperaram para que se verificasse a prestação de serviços sem cobertura contratual válida deve ser apurada, instaurando-se processo administrativo disciplinar com esse objetivo específico, sob pena de responsabilidade também dos que se omitirem nesta apuração.

f) apenas a força maior ou o caso fortuito pode escusar a responabilidade dos agentes referidos na letra " $\mathrm{e}$ " supra. 